GÓMEZ-JARA, CARLOS. "Responsabilidad penal de todas las personas jurídicas?

Una antecrítica al símil de la ameba acuñado por Alex van Weezel".

Polit. crim. Vol. 5, No 10 (Diciembre 2010), Doc. 1, pp. 455-475.

[http://www.politicacriminal.cl/Vol_05/n_10/Vol5N10D1.pdf]

\title{
¿Responsabilidad penal de todas las personas jurídicas? Una antecrítica al símil de la ameba acuñado por Alex Van Weezel
}

\author{
Carlos Gómez-Jara Díez \\ Profesor de Derecho penal (UAM, España) \\ Abogado (Director Corporate Defense)
}

\section{Nota previa}

1.1. Cuando en el año 2005 propuse por primera vez el concepto de imputabilidad empresarial, ${ }^{1}$ lo cierto es que en el ámbito académico y legislativo no tuvo una acogida inmediata. No fue hasta que la magnífica monografía de Nieto Martín sobre responsabilidad penal de las personas jurídicas tres años después se hiciera eco de dicha propuesta, ${ }^{2}$ cuando la comunidad científica empezó a hablar de personas jurídicas imputables e inimputables. En tiempos recientes, en el debate chileno, mi buen amigo Alex van Weezel ha publicado un artículo en contra de la responsabilidad penal de las personas jurídicas debido a que la autorreferencialidad de éstas "nunca superará a la que posee una ameba" "o cual debería abocar al autor a debatir sobre la autorreferencialidad (organizativa) como criterio de imputabilidad (organizativa). Desgraciadamente, en dicho artículo se echa de menos una discusión ${ }^{4}$ sobre estos argumentos - los cuales, por lo demás, fueron los que en su día me llevaron a formular el concepto de imputabilidad empresarial sobre la base de la autorreferencialidad suficiente de determinadas organizaciones empresariales - . Pues bien, debido a que el núcleo de la crítica de Van Weezel a este respecto $^{5}$ se encuentra desarrollado en trabajos de diversos autores - especialmente los de

\footnotetext{
*cgj@corporatedefense.es

1 GÓMEZ-JARA DÍEZ, Carlos, “¿Imputabilidad de las personas jurídicas?”, en: BAJO FERNÁNDEZ, Miguel; JORGE BARREIRO, Agustín; SUÁREZ GONZÁLEZ, Carlos (eds.), Libro Homenaje a D. Gonzalo Rodríguez Mourullo, 2005, pp. 163-182; GÓMEZ-JARA DÍEZ, Carlos, La culpabilidad penal de la empresa, 2005, pp. 241 y ss. [=Fundamentos modernos de la culpabilidad empresarial. Santiago de Chile: Ediciones Jurídicas de Santiago, 2008, pp. 285 y ss.].

${ }^{2}$ NIETO MARTÍN, La responsabilidad penal de las personas jurídicas. Un modelo legislativo, 2008, pp. 169 y ss.

${ }^{3}$ VAN WEEZEL, Alex, “Contra la responsabilidad penal de las personas jurídicas”, Polit. crim. Vol. 5, No 9 (Julio 2010), Art. 3, pp. 114-142. [http://www.politicacriminal.cl/Vol_05/n_09/Vol5N9A3.pdf], p. 125. Por lo demás, dicha afirmación apodíctica no es avalada por el autor con referencia a literatura alguna. Se trata de una petitio principii hábilmente construida. Desgraciadamente para el autor de la misma, las referencias en sentido contrario en la literatura sociológica y filosófica de finales del siglo XX y principios del XXI son abrumadoras, como se puede comprobar en las notas al pie contenidas en el presente trabajo.

${ }^{4}$ Para un análisis en profundidad de estos aspectos vid. V. FREIER, "Zurück hinter die Aufklärung: Zur Wiedereinführung von Verbandsstrafen”, GA 2009, pp. 98 y ss. De manera más reciente, VON FREIER, "Selbstbelastungfreiheit für Verbandspersonen?", ZStW $\mathrm{N}^{\circ} 122$ (2010), pp. 117 y ss.

${ }^{5}$ VAN WEEZEL, "Contra la responsabilidad penal", cit. nota n ${ }^{\circ}$ 3, pp. 114-142; pp. 125-126: "Esta evidencia no es sino el reflejo de una realidad más profunda: la tenue identidad de las personas jurídicas, su carácter instrumental y, en directa relación con ello, su absoluta dependencia respecto de las decisiones que toman las personas naturales que las administran directamente o a través de otros. De allí que las personas jurídicas se "creen" y "supriman" a voluntad, según lo requieran los negocios e intereses de quienes las manejan. Es
} 
GÓMEZ-JARA, CARLOS. "Responsabilidad penal de todas las personas jurídicas? Una antecrítica al símil de la ameba acuñado por Alex van Weezel”.

Jakobs, v. Freier y Rodríguez Mourullo - que abordo en aquel artículo embrionario de 2005, y toda vez que el mismo puede resultar de difícil acceso para el público chileno, la revista de política criminal ha tenido la amabilidad de publicar dicho trabajo para fomentar el debate constructivo al respecto.

1.2. El núcleo de la debilidad del argumento de Van Weezel reside en la falacia de la aseveración sobre la complejidad de determinados sistema organizativos. Dado que el propio autor hace referencia a "todo sistema relativamente complejo" debería indagarse sobre qué dice la teoría más versada en sistemas: la teoría de sistemas. Pues precisamente ésta, apoyándose en los avances de las ciencias de la comunicación, parte de la base de que tanto conciencia como comunicación muestran los mismos caracteres de autorreferencialidad, recursividad y reflexión. En resumen, la crítica de Van Weezel resulta errada por los siguientes motivos.

La autorreferencialidad comunicativa a la que acabamos de hacer referencia se da en dos sistemas claves: el sistema jurídico (Derecho) y el sistema organizativo (empresa). Por lo que al primero se refiere, la autorreferencialidad de la comunicación conlleva que el sistema jurídico no tenga acceso directo ni al interior de la conciencia humana (sistema psíquico), ni al interior de la organización empresarial (sistema organizativo). Ambos sistemas, tanto psíquico como organizativo, pueden aspirar, como mucho, a mostrar indicios racionales de una autorreferencialidad suficiente, ya que éstos conforman la base sobre la cual el sistema jurídico-penal atribuye la «personalidad». Dicha autorreferencialidad se plasma, en terminología teórico-sistémica, en la constitución de los sistemas autopoiéticos de orden superior (High Order Autopoyetic Systems). Dado que la constitución del sistema psíquico (ser humano) como un sistema autopoiético de orden superior no es cuestionada por la doctrina penal mayoritaria, conviene centrar la atención en el sistema organizativo (la empresa) para responder a la cuestión: ¿puede una organización empresarial convertirse en un sistema autopoiético de orden superior?

A lo largo de las últimas décadas, Gunther Teubner ha venido elaborando los presupuestos de cómo se constituye una empresa en un sistema autopoiético de orden superior. Así, tal y como señala expresamente este autor, la organización empresarial sale de su minoría de edad en el momento en el que se produce una vinculación hipercíclica entre los caracteres autorreferenciales del sistema organizativo: es decir, una doble autorreferencialidad. Expresado de otra manera: a lo largo del tiempo se produce una acumulación de círculos autorreferenciales en el ámbito empresarial hasta llegar al encadenamiento hipercíclico de los mismos, momento en el cual emerge verdaderamente el actor corporativo (corporate actor) como sistema autopoiético de orden superior.

posible que en ellas pueda desarrollarse con el paso de los años un cierto grado de autorreferencialidad, como el que existe en todo sistema relativamente complejo, pero dicha autorreferencialidad nunca superará a la que posee una ameba. Por la misma razón no puede hablarse de autoconciencia o autocomprensión, de ese "volver sobre sí mismo" que es el gesto propio del espíritu. Y cuando en la imposición del castigo no está presente la posibilidad de una toma de conciencia, sólo subsisten la coacción, la ingeniería social y la protección de intereses más o menos cosificados". 
Por lo tanto, lo decisivo en el marco de esta discusión es que tanto el sistema psíquico como el sistema organizativo deben desarrollar una determinada complejidad interna suficiente para poder ser consideradas personas en Derecho penal. Así, la complejidad interna suficiente es un presupuesto para el desarrollo de una autorreferencialidad bastante que permita la autodeterminación del propio sistema con respecto al entorno, cuestión decisiva para el nacimiento de la responsabilidad penal. En este sentido se puede establecer, de nuevo, una equivalencia funcional entre el desarrollo de una complejidad interna suficiente en el ser humano y en la organización empresarial. Así, al igual que el niño no es imputable en Derecho penal individual hasta que su sistema psíquico no es suficientemente complejo, esto es, hasta que no ha alcanzado un determinado nivel interno de autorreferencialidad - autoconciencia -, tampoco la empresa puede considerarse imputable en el Derecho penal empresarial hasta que su sistema organizativo no es suficientemente complejo, esto es, hasta que no ha alcanzado un determinado nivel interno de autorreferencialidad - autoorganización -. Por tanto, las empresas deben también superar ese umbral de complejidad interna suficiente y de autorreferencialidad bastante para poder ser consideradas personas en Derecho penal. Dicho umbral, por lo demás, se establece, tanto en el ámbito del Derecho penal individual como en el del Derecho penal empresarial, normativamente.

1.3. Con independencia de la falta de asunción del criterio de la imputabilidad empresarial en la ley $\mathrm{n}^{\circ} 20.393$, no puede sino afirmarse que se trata, en términos generales, de una excelente legislación que sitúa a Chile a la vanguardia de los ordenamientos jurídicos en esta materia. La adopción de un modelo de autorresponsabilidad penal empresarial ${ }^{6}$ constituye una lógica consecuencia de la estrecha vinculación existente entre autorregulación, ciudadanía corporativa y cumplimiento de la legalidad ${ }^{7}$. Adicionalmente, el establecimiento en la propia ley de criterios claros respecto del sistema de imputación y de la exclusión de responsabilidad contribuye de manera decisiva a la necesaria seguridad jurídica que precisa cualquier operador jurídico - al contrario de lo que desgraciadamente ha sucedido en España con la reforma aprobada el 23 de junio de 2010 -. Las reflexiones que siguen a continuación pretenden únicamente servir al debate académico y, en su caso, a una reforma futura de la legislación chilena en la que se distinga entre personas jurídicas imputables e inimputables.

\section{Introducción}

En su célebre manual de 1978 Rodríguez Mourullo escribía que las personas jurídicas "carecen de la voluntad en sentido psicológico", por lo que "en verdad no es que la persona jurídica "concluya" por sí misma contratos, sino que queda vinculada por los contratos que celebran en su nombre las personas individuales que actúan como órganos suyos". 8 Los argumentos de Rodríguez Mourullo en este ámbito han sido recepcionados, como en tantos

\footnotetext{
${ }^{6}$ Sobre la acuñación de dicho concepto vid. GÓMEZ-JARA DÍEZ, Carlos, Modelos de autorresponsabilidad penal empresarial. Propuestas globales contemporáneas. Universidad Externado de Colombia, 2008.

${ }^{7}$ Vid. con más detalle GÓMEZ-JARA DÍEZ, Fundamentos modernos, cit. nota ${ }^{\circ} 1$, pp. 292 y ss.; GÓMEZJARA DÍEZ, Carlos, "La incidencia de la autorregulación en el actual debate legislativo y doctrinal sobre la responsabilidad penal de las personas jurídicas", en: NIETO MARTÍN / ARROYO JIMÉNEZ (Dirs.), Autorregulación y sanciones. Madrid: Lex Nova, 2008 pp. 256-313.

${ }^{8}$ RODRÍGUEZ MOURULLO, Derecho penal. Parte General, 1978, p. 227.
} 
GÓMEZ-JARA, CARLOS. "Responsabilidad penal de todas las personas jurídicas? Una antecrítica al símil de la ameba acuñado por Alex van Weezel”.

otros, por destacados miembros de la dogmática penal española. ${ }^{9}$ Fruto quizá de la coincidencia - o quizá del hecho de llevar razón - otro gran maestro del Derecho penal contemporáneo, Günther Jakobs, escribía recientemente una crítica a la posibilidad de concebir una verdadera culpabilidad de las personas jurídicas basándose en argumentos semejantes, si bien desde una fundamentación diferente. Así, señalaba, por un lado, que, caso de imputarle a la persona jurídica la culpabilidad de su órgano, la necesaria consecuencia pasa por "desimputársela" a éste $-{ }^{10}$ lo cual sería, según este autor, políticocriminalmente inaceptable -; por otro lado, si se construye una culpabilidad propia de la persona jurídica - es decir, no imputándole la de su órgano -, entonces, en realidad, no se trata de una verdadera culpabilidad ya que la persona jurídica carece de autoconciencia ${ }^{11} \mathrm{y}$, consecuentemente, "no se sabe a sí misma libre". 12 En definitiva, estas argumentaciones conducen irremediablemente a la consecuencia de que las personas jurídicas no son imputables en Derecho penal.

A la vista de la reciente introducción de la responsabilidad penal empresarial en diversas legislaciones europeas, ${ }^{13}$ el artículo 31.2 del vigente Código penal, en las líneas que siguen

${ }^{9}$ GRACIA MARTÍN, "La cuestión de la responsabilidad penal de las propias personas jurídicas", en: MIR PUIG / LUZÓN PEÑA (eds.), Responsabilidad penal de las empresas y sus órganos y responsabilidad por el producto, 1996, p. 42; SUÁREZ GONZÁLEZ, "La responsabilidad penal de las personas jurídicas en el Derecho europeo", en: Estudios del Ministerio Fiscal 1994, p. 846. Vid. un planteamiento semejante en ROXIN, Derecho penal. Parte General, (traducción de Diego-Manuel Luzón Peña, Miguel Díaz y García Conlledo y Javier de Vicente Remesal), 1997 § 8/55: "les falta una sustancia psíquico-espiritual, no pueden manifestarse a sí mismas" [cfr. no obstante sus reflexiones en IBíD., § 8/56c; İD., "¿Tiene futuro el Derecho penal?", PJ N ${ }^{\circ} 49$ (1998), p. 391]. Vid. también en este sentido CEREZO MIR, Derecho penal. Parte General. Vol. II. 6a ed. 1998, p. 70; MIR PUIG, "Una tercera vía en materia de responsabilidad penal de las personas jurídicas”, RECPC $\mathrm{N}^{\circ} 06$ (2004), p. 9.

10 JAKOBS, "Strafbarkeit juristischer Personen?", en: PRITTWITZ ET. AL. (eds.), Festschrift für Klaus Lüderssen, 2002, p. 565; siguiéndole, si bien con una formulación más teórico-sistémica, FEIJÓO SÁNCHEZ, Sanciones para empresas por delitos contra el medio ambiente. Presupuestos dogmáticos y criterios de imputación para la intervención del Derecho penal contra las empresas, 2003, pp. 66, 121. Para un análisis en profundidad de este argumento y su refutación vid. GÓMEZ-JARA DÍEZ, La culpabilidad penal, cit. nota $\mathrm{n}^{\circ} 1$, pp. 109 y ss., 113 y ss.; ORCE, "Responsabilidad penal de las personas jurídicas", en: MONTEALEGRE LYNETT (Coord.); El funcionalismo en Derecho penal. Libro Homenaje al Profesor Günther Jakobs. Tomo II, 2003, pp. 371 y ss., 381 y ss.

${ }^{11}$ JAKOBS, en: PRITTWITZ, Festschrift für Klaus Lüderssen, cit. nota $\mathrm{n}^{\circ} 10$, pp. 568 y ss.; FEIJÓO SÁNCHEZ, Sanciones para empresas, cit. nota ${ }^{\circ} 10$, pp. 84 y ss.; vid. en esta línea, desde premisas, no obstante, diferentes SILVA SÁNCHEZ, "La responsabilidad penal de las personas jurídicas y las consecuencias accesorias del art. 129 del Código Penal español”, en: GARCÍA CAVERO (Coord.), La responsabilidad de las personas jurídicas, órganos y representantes, 2002, pp. 171, 176; ÍD., Normas y acciones en Derecho penal, 2003, pp. 83, 86. Cfr. las contrarréplicas contenidas en GÓMEZ-JARA DÍEZ, La culpabilidad penal, cit. nota $n^{\circ} 1$, pp. 113 y ss.; ORCE, en: MONTEALEGRE LYNETT, El funcionalismo en Derecho penal, cit. nota $\mathrm{n}^{\circ} 10$, pp. 371 y ss., 376,378 y ss., 383 y ss.

${ }^{12}$ JAKOBS, en: PRITTWITZ, Festschrift für Klaus Lüderssen, cit. nota ${ }^{\circ} 10$, p. 571. Dicho argumento es tomado básicamente de v. FREIER, Kritik der Verbandsstrafe, 1998, pp. 93, 115, 122.

${ }^{13}$ En este sentido deben destacarse la legislación suiza (Arts. 100quarter y 100quinquies del Código penal suizo) - de entrada en vigor el 12 de diciembre de 2002 - y la polaca (Ley sobre la responsabilidad penal de los sujetos colectivos por hechos castigados con penas) - en vigor desde el 28 de noviembre de $2003-$. En general sobre la tendencia criminalizadora europea vid. HEINE, "La responsabilidad penal colectiva: una tarea pendiente a la luz de la reciente evolución europea" (trad. GÓMEZ-JARA DÍEZ, Carlos), en: GÓMEZJARA DÍEZ (ed.), Modelos de autorresponsabilidad penal empresarial, 2005; sobre la regulación suiza vid. HEINE, "Das kommende Unternehmensstrafrecht (Art. $1004^{\circ}$ f). Entwicklung und Grundproblematik", 
se utilizará el razonamiento antecitado para aprender una importante lección que estas críticas enseñan, pero que, probablemente, no estaba en la mente de sus autores: que existen personas jurídicas imputables y personas jurídicas inimputables. Ya sólo la formulación del problema cause, quizá, cierto estupor; sobre todo entre los partidarios de la responsabilidad penal de las personas jurídicas. Así, suficientemente difícil se antojaba ya la tarea de fundamentar que las personas jurídicas podían ser responsables penalmente como para tener que asumir que hay que distinguir entre personas jurídicas a la hora de establecer su culpabilidad jurídico-penal. De hecho, se trata de una cuestión que, hasta el momento y por lo que se alcanza a ver, no se ha planteado explícitamente. Es decir, no se ha planteado entre los defensores de este tipo de responsabilidad el problema de qué personas jurídicas pueden realmente mostrar una culpabilidad jurídico-penal. ${ }^{14}$ Prima facie parece darse por sentado que las personas jurídicas tienen capacidad de culpabilidad jurídico-penal y, en este sentido, todas son imputables.

Ahora bien, si no todos los seres humanos son susceptibles de ser considerados sujetos activos del Derecho penal individual ¿por qué todas las personas jurídicas sí en el Derecho penal empresarial? ¿No respondería más a la lógica jurídico-penal que al igual que no todos los seres humanos son capaces de responder penalmente, tampoco deben poder hacerlo todas las personas jurídicas? La tesis que aquí se desarrollará consiste precisamente en sostener que, en el seno de un verdadero o genuino Derecho penal empresarial, debe diferenciarse entre personas jurídicas con capacidad de culpabilidad (empresarial) y personas jurídicas inimputables - frente a las que cabe, por ejemplo, imponer cierto tipo de medidas o sanciones - . Para ello, la siguiente contribución partirá - Infra 3 - con una exposición de los fundamentos básicos del concepto clave de toda esta problemática: la culpabilidad empresarial. En concreto se parte del concepto constructivista de culpabilidad empresarial cuya fundamentación pormenorizada no puede, por motivos obvios, desarrollarse en una contribución de este tipo. ${ }^{15}$ Una vez sentadas dichas premisas, se analizará cómo afecta al contenido de las críticas anteriormente citadas - Infra 4 - en aras de exponer, a continuación - Infra 5 - las consecuencias que de ello se derivan. Por último - Infra 6 -, se intentará demostrar por qué resulta político-criminalmente más adecuado llevar a cabo un planteamiento de estas características.

\section{Lineamientos generales del concepto constructivista de culpabilidad empresarial}

3.1. El concepto constructivista de culpabilidad adquiere esta denominación del hecho de estar basado en el constructivismo operativo, ${ }^{16}$ corriente epistemológica de la teoría de los

ZStrR $\mathrm{N}^{\circ} 121$ (2003), pp. 24 y ss.; respecto de la reciente normativa polaca vid. WEIGEND / NAMYSLOWSKA-GABRYSIAK, "Die strafrechtliche Verantwortlichkeit juristischer Personen im polnischen Recht", ZStW N 114 (2004), pp. 541 y ss.

${ }^{14}$ Esta discusión no debe confundirse con la problemática relativa a si las entidades de Derecho público pueden estar sujetas a un régimen de responsabilidad penal o la referida a los presupuestos de imputación en función de las diversas formas jurídico-societarias.

${ }^{15}$ Dicha fundamentación puede encontrarse en GÓMEZ-JARA DÍEZ, La culpabilidad penal, cit. nota $\mathrm{n}^{\circ} 1$, pp. 201 y ss., 208 y ss., 219 y ss. y 247 y ss.

${ }^{16}$ Sobre el constructivismo operativo vid. ampliamente, GÓMEZ-JARA DÍEZ, "Distinciones teóricas en la observación del sistema jurídico-penal: breves apuntes sobre la teoría de reflexión del Derecho penal", en: MONTEALEGRE LYNETT (Coord.), El funcionalismo en Derecho penal, cit. nota n 10, pp. 15 y ss.; ÍD., 
GÓMEZ-JARA, CARLOS. "Responsabilidad penal de todas las personas jurídicas? Una antecrítica al símil de la ameba acuñado por Alex van Weezel”.

sistemas sociales autopoiéticos. ${ }^{17}$ Esta teoría que, como bien es sabido, no cuenta con excesivos partidarios en el ámbito del Derecho penal tradicional, ${ }^{18}$ parece haber encontrado cierto acomodo en el ámbito del Derecho penal empresarial, de tal manera que son varios los autores que, explícita o implícitamente, se remiten a ella en la fundamentación de sus posiciones. ${ }^{19}$ Probablemente, la diferencia entre la mayoría de dichos planteamientos y el aquí defendido es que en éste se pretenden asumir todas las consecuencias, tanto epistemológicas como de aplicación a otros sistemas sociales, que dicha teoría social conlleva. ${ }^{20}$ Lo relevante a estos efectos es que, desde esta perspectiva, tanto la organización empresarial como el ser humano, como también el Derecho, se consideran sistemas

La culpabilidad de las personas jurídicas, § VI. 1.2.; ÍD., "Teoría de sistemas y Derecho penal: hacia una ciencia constructivista del Derecho penal”, en: GÓMEZ-JARA DÍEZ (ed.), Teoría de sistemas y Derecho penal: Fundamentos y posibilidades de aplicación, 2005, con abundantes referencias.

${ }^{17}$ Sobre la teoría de los sistemas sociales autopoiéticos vid. de manera introductoria las obras de Niklas Luhmann: LUHMANN, Einführung in die Systemtheorie; BAECKER, Dirk (ed.), 2002, pp. 11 y ss.; ÍD., Soziale Systeme. Grundriß einer allgemeinen Theorie, 1984, passim; ÍD., Die Gesellschaft der Gesellschaft, 2 Tomos, 1997, passim. Resultan sumamente didácticos los trabajos de KNEER / NASSEHI, Niklas Luhmanns Theorie sozialer Systeme. $4^{\mathrm{a}}$ ed. 2000, pp. 33 y ss.; WILLKE, Systemtheorie I: Grundlagen. $6^{\mathrm{a}}$ ed. 2000, pp. 1 y ss. En la Ciencia penal española resulta fundamental la obra de PIÑA ROQUEFORT, Rol social y sistema de imputación. Una aproximación al Derecho penal a la luz de la teoría de sistemas, 2004. Vid. además el estudio y las referencias contenidas en GÓMEZ-JARA DÍEZ, "Teoría de sistemas y Derecho penal: culpabilidad y pena en una teoría constructivista del Derecho penal", en: GÓMEZ-JARA DÍEZ (ed.), Teoría de sistemas y Derecho penal, cit. nota $\mathrm{n}^{\circ} 16$. En general vid. las contribuciones contenidas en GÓMEZ-JARA DÍEZ (ed.), Teoría de sistemas y Derecho penal, cit. nota $n^{\circ} 16$.

${ }^{18}$ Vid. por todos el completo estudio de FEIJÓO SÁNCHEZ, "La normativización del Derecho penal: ¿Hacia una teoría sistémica o intersubjetiva de la comunicación?", en: GÓMEZ-JARA DÍEZ (ed.), Teoría de sistemas y Derecho penal, cit. nota ${ }^{\circ} 16$.

${ }^{19}$ Vid. BOTTKE, "Standortvorteil Wirtschaftskriminalrecht: Müssen Unternehmen "strafmündig" werden? Bermerkungen zum Stand des Wirtschaftskriminalrechts in der Bundesrepublik Deutschland", wistra 1997, pp. 251 con nota 94, 253; ÍD, Assoziationsprävention. Zur heutigen Diskussion der Strafzwecke, 1995, pp. 49, 310 con nota 1002 entre otros lugares; ÍD., "La actual discusión sobre las finalidades de la pena", en: SILVA SÁNCHEZ (ed. española), Política criminal y nuevo Derecho Penal. Libro Homenaje a Claus Roxin, 1997, pp. 42 y s.; HEINE, Die Strafrechtliche Verantwortlichkeit von Unternehmen. Von individuellen Fehlverhalten zu kollektiven Fehlentwicklungen insbesondere bei Großrisiken, 1995, pp. 79 y s.; LAMPE, "Systemsunrecht und Unrechtssystem", ZStW No 106 (1994), pp. 690 y s.; LÜTOLF, Strafbarkeit der juristischen Person, 1997, Cap. III; ROGALL, en: BOUJONG (ed.), Karlsruher Kommentar zum Gesetz über Ordnungswidrigkeiten, $2^{\mathrm{a}} \mathrm{ed} ., 2000, \S 30 / 10$; ROTSCH, Individuelle Haftung in Großunternehmen. Plädoyer für den Rückzug des Umweltstrafrechts, 1998, pp. 81 y ss.; SCHÜNEMANN, "Plädoyer zur Einführung einer Unternehmenskuratel", en: SCHÜNEMANN (ed.), Deutsche Wiedervereinigung: Die Rechtseinheit / Arbeitskreis Strafrecht. Bd. III. Unternehmenskriminalität, 1996, p. 137; ÍD., "Art. 4. Maßnahmen gengen Unternehmen", en: SCHÜNEMANN (ed.), Deutsche Wiedervereinigung: Die Rechtseinheit / Arbeitskreis Strafrecht. Bd. III Unternehmenskriminalität, 1996, pp. 168, 170 ha tomado "como fundamento legitimador (..) la teoría de los sistemas autopoiéticos limitada", 175; ÍD., "La punibilidad de las personas jurídicas desde la perspectiva europea" (traducción a cargo de Enrique Peñaranda Ramos), en: AA.VV., Hacia un Derecho penal económico europeo. Jornadas en honor al Profesor Klaus Tiedemann, 1995, pp. 572, 579 y s.; ÍD., "Criticising the notion of a Genuine Criminal Law Against Legal Entities", en: ESER / HEINE / HUBER (eds.), Criminal Responsibility of Collective and Legal Entities, 1999, p. 230: "el único concepto que queda para justificar un verdadero Derecho penal corporativo es el modelo de la teoría de sistemas"; SCHWINGE, Strafrechtliche Sanktionen gegenüber Unternehmen im Bereich des Umweltstrafrechts, 1996, pp. 206 y ss.; ZÚNIGA RODRÍGUEZ, Bases para un modelo de imputación de responsabilidad a las personas jurídicas, $2^{\mathrm{a}}$ ed. 2003, pp. 223 y s.

${ }^{20}$ Vid. GÓMEZ-JARA DÍEZ, La culpabilidad penal, cit. nota n 1, pp. 211 y ss. 
Polit. crim. Vol. 5, № 10 (Diciembre 2010), Doc. 1, pp. 455-475.

[http://www.politicacriminal.cl/Vol_05/n_10/Vol5N10D1.pdf]

\author{
autopoiéticos - autoproducidos -, eso sí, con diferentes modos de reproducción \\ autopoiética. $^{21}$
}

3.2. Centrando la atención en el sistema organizativo empresarial, éste - al igual que el ser humano - comienza a desarrollar con el tiempo una complejidad interna que deviene en una capacidad de autoorganización, autodeterminación y autoconducción tal, que resulta lógico - y necesario - atribuir a la empresa cierta competencia sobre su ámbito de organización. ${ }^{22}$ Desde una perspectiva tradicional del delito puede afirmarse que la capacidad de acción se ve así sustituida por una capacidad de organización ${ }^{23}$, de tal manera que si bien resulta complicado afirmar que una empresa actúa por sí misma, dichas dificultades desaparecen considerablemente cuando se sostiene que, llegado un determinado nivel de complejidad interna, la empresa comienza a organizarse a sí misma, a autoorganizarse. ${ }^{24}$

3.3. Como consecuencia de esta situación no resulta extraño que las organizaciones empresariales hayan empezado a participar en la vida social y jurídica de manera significativa. Tanto es así, que bien podría afirmarse que desempeñan un rol absolutamente decisivo en la configuración de la identidad de la sociedad moderna. ${ }^{25}$ A partir de dicha

21 Respecto del ser humano como sistema autopoiético vid. LUHMANN, "Die Autopoiesis des Bewu tseins", en: ÍD., Soziologische Aufklärung. Bd. VI: Die Soziologie und der Mensch, 1995, pp. 55 y ss.; en relación con la organización como sistema autopoiético vid. ahora sólo LUHMANN, Organisation und Entscheidung, 2000, pp. 39 y ss.; finalmente, sobre el Derecho como sistema autopoiético vid. LUHMANN, Das Recht der Gesellschaft, 1993, pp. 38 y ss.; TEUBNER, Recht als autopoietisches System, 1989, pp. 36 y ss.; ÍD., "El Derecho como sujeto epistémico: Hacia una epistemología constructiva del Derecho" (traducción de Carlos Gómez-Jara Díez), DOXA N 25 (2002), pp. 533 y ss.

${ }^{22}$ Vid. con diferentes matices BOTTKE, Assoziationsprävention, cit. nota ${ }^{\circ} 19$, pp. 48 y ss., 63 y ss.; ÍD., en: SILVA SÁNCHEZ (ed.), Política criminal y nuevo Derecho Penal, cit. nota $\mathrm{n}^{\circ} 19$, p. 42; HEINE, Strafrechtliche Verantwortlichkeit von Unternehmen, pp. 287 y ss.; LAMPE, "Zur ontologischen Struktur des strafbaren Unrechts", en: WEIGEND / KÜPPER (eds.), Festschrift für Hans Joachim Hirsch, 1999, pp. 86 y ss., 91 y ss., 94.

23 Especialmente ilustrativos en este sentido HEINE, "Modelle originärer (straf-)rechtlicher Verantwortlichkeit von Unternehmen", en: HETTINGER (ed.), Reform des Sanktionsrecht. Bd. III: Verbandstrafe, 2002, p. 141; ÍD., "Plädoyer für ein Verbandsstrafrecht als "zweite Spur"”' en: ALWART (ed.), Verantwortung und Steuerung von Unternehmen in der Marktwirtschaft, 1998, p. 103; ÍD., "Die strafrechtliche Verantwortlichkeit von Unternehmen: internationale Entwicklung - nationale Konsequenzen", $\ddot{O} J Z \mathrm{~N}^{\circ} 51$ (1996), p. 218 quien establece una equivalencia funcional entre dominio del hecho [Derecho penal individual] y dominio de la organización (funcionalmente sistémico) [Derecho penal empresarial]; LAMPE, en: WEIGEND / KÜPPER (eds.), Festschrift für Hans Joachim Hirsch, pp. 92, 94 quien establece que las personas físicas tienen capacidad de acción (Handlungsvermögen) mientras que las personas jurídicas tienen capacidad de organización (Organisationsvermögen), resultando ambas capacidades idénticas a los efectos de producir injustos sociales.

${ }^{24}$ Dicho planteamiento viene avalado, además de por las aportaciones de la teoría de los sistemas sociales autopoiéticos, por numerosas teorías de la organización y del management modernas [vid., por ejemplo, BAUSOR, "Enterpreneurial Imagination, Information, and the Evolution of the Firm", en: ENGLAND (ed.), Evolutionary Concepts in Contemporary Economics, 1994, pp. 179 y ss, 181; DRAZIN / SANDERLANDS, "Autogenesis: A Perspective on the Process of Organizing", Organization Science N 3 (1992), pp. 230 y ss.; las contribuciones contenidas en ULRICH / PROBST, Selforganization and Managament of Social Systems: Insights, Doughts, and Questions. Berlin, 1984 y PROBST / SIEGWART, Integriertes Management: Bausteine der systemorientierten Managements. Festschrift zum 65 Geburstag von Prof. Dr. h.c. Hans Ulrich, $1985]$.

${ }^{25}$ No en vano se ha descrito la sociedad moderna como una sociedad de las organizaciones [vid. PERROW, "A Society of Organizations", en: HALLER / HOFFMANN-NOWOTNY / ZAPF (eds.), Kultur und 
GÓMEZ-JARA, CARLOS. "Responsabilidad penal de todas las personas jurídicas? Una antecrítica al símil de la ameba acuñado por Alex van Weezel”.

constatación se puede construir un concepto de culpabilidad empresarial que, si bien no sea idéntico al concepto de culpabilidad individual, sí que resulte funcionalmente equivalente. ${ }^{26}$ Es decir, culpabilidad empresarial y culpabilidad individual no son iguales, pero sí funcionalmente equivalentes. ${ }^{27}$ En concreto, el concepto constructivista de culpabilidad empresarial se basa en tres equivalentes funcionales que se corresponden con los tres pilares del concepto de culpabilidad individual: la fidelidad al Derecho como condición para la vigencia de la norma, el sinalagma básico del Derecho penal y, por último, la capacidad de cuestionar la vigencia de la norma. ${ }^{28}$

3.4. El primer equivalente funcional se fundamenta en el hecho de que, en la sociedad moderna, la vigencia de determinadas normas depende en gran medida de la creación y mantenimiento de una cultura empresarial de fidelidad al Derecho. Así, el modelo descentralizado de organización social que surgió en el ámbito individual con motivo de la "desmitificación del mundo", ${ }^{29}$ ha tenido lugar en el ámbito empresarial a lo largo del siglo XX gracias, entre otras cosas, a la "desmitificación del Estado". ${ }^{30}$ De esta manera nace el conocido fenómeno de la autorregulación empresarial como un reflejo de la incapacidad estatal para controlar ciertos riesgos característicos de la sociedad post-industrial moderna. $^{31}$ Ello ha provocado que dicho control y gestión de riesgos se haya descentralizado hacia unas organizaciones empresariales que, en virtud de su tamaño y

Gesellschaft, 1989, pp. 265 y ss.; vid. también LADEUR, " $\mathrm{Zu}$ einer Grundrechtstheorie der Selbstorganisation des Unternehmens", en: STEIN / FABER (eds.), Auf einem dritten Weg. Festschrift für Helmut Ridder, 1989, p. 180].

${ }^{26}$ Sobre el método del equivalente funcional vid. LUHMANN, Zweckbegriff und Systemrationalität. Über die Funktion von Zwecken in sozialen Systemen, 1968, pp. 162 y ss.; ÍD., Soziale Systeme, pp. 83 y ss. con referencias ÍD., Die Wissenschaft der Gesellschaft, 1990, pp. 368, 417 y ss. Dicho concepto ha sido introducido en el ámbito del Derecho penal empresarial por HEINE [vid. claramente ÍD., "New Developments in Corporate Criminal Liability in Europe: Can Europeans learn from the American Experience - or Viceversa?", Saint Louis - Warsaw Transatlantic Law Review 1998, pp. 187 y s.].

${ }^{27}$ Desde esta perspectiva resulta fundamental, por tanto, indicar qué función cumple el Derecho penal, puesto que será a partir de dicha función que se pueda considerar la equivalencia entre culpabilidad individual y culpabilidad empresarial. En este sentido, el concepto constructivista de culpabilidad considera que la función del Derecho penal consiste en el mantenimiento de la vigencia normativa [vid. a este respecto JAKOBS, Sociedad, norma y persona en una teoría de un Derecho penal funcional (traducción de Manuel Cancio Melia y Bernardo Feijóo Sánchez), 1996, p. 16; GÓMEZ-JARA DÍEZ, La culpabilidad penal, cit. nota nº 1, pp. 213 y ss.

${ }^{28}$ Para el desarrollo de dichos pilares en el ámbito de la culpabilidad individual vid. GÓMEZ-JARA DÍEZ, La culpabilidad penal, cit. nota ${ }^{\circ} 1$, pp. 258 y ss., 273 y ss., 285 y ss.

${ }^{29}$ WEBER, Gesammelte Aufsätze zur Wissenschaftslehre (edición de Winckelmann). $3^{\mathrm{a}}$ ed., 1968, pp. 582 ss., 594.

${ }^{30}$ WILLKE, Entzauberung des Staates, 1983.

${ }^{31}$ Vid. entre muchos otros DI FABIO, "Verwaltung und Verwaltungsrecht zwischen gesellschaftlicher Selbstregulierung und staatlicher Steuerung", en: Veröffentlichungen der Vereinigung der deutschen Staatsrechtslehrer 6 (1997), pp. 235 ss.; LADEUR, "Die Regulierung von Selbstregulierung und die Herausbildung einer "Logik der Netzwerke". Rechtliche Steuerung und die beschleunigte Selbsttransformation der postmodernen Gesellschaft", en: Regulierte Selbstregulierung als Steuerungskonzept des Gewährleistungsstaates. Die Verwaltung, Beiheft 4 (2001), pp. 59 y ss.; ESTEVE PARDO, Autorregulación. Génesis y efectos, 2002, pp. 35 y s. y passim; DARNACULLETA I GARDELLA, Autorregulación y Derecho público: la autorregulación regulada, 2005, pp. 38 y ss., 52 y ss., 140 y ss. y passim. 
Polit. crim. Vol. 5, № 10 (Diciembre 2010), Doc. 1, pp. 455-475.

[http://www.politicacriminal.cl/Vol_05/n_10/Vol5N10D1.pdf]

complejidad interna, no admiten una regulación - intervención - directa estatal externa, ${ }^{32}$ sino que, como mucho, puede aspirarse a un control del contexto (Kontextsteuerung) característico del Derecho reflexivo. ${ }^{33}$ A la vista de esta situación resulta necesario y adecuado imponer a dichas organizaciones empresariales la obligación primordial que afecta a toda persona jurídico-penal: la obligación de fidelidad al Derecho, lo cual se concreta en la institucionalización de una cultura empresarial de fidelidad al Derecho. ${ }^{34} \mathrm{El}$ reconocimiento de una esfera de autonomía a la empresa con la consiguiente obligación de fidelidad al Derecho provoca, al igual que lo hizo en el individuo, ${ }^{35}$ el nacimiento del ciudadano (corporativo) fiel al Derecho. Por tanto, el rol que garantiza el Derecho penal (empresarial) es el del rol del ciudadano (corporativo) fiel al Derecho y, en consecuencia, la no institucionalización de esa cultura empresarial de fidelidad al Derecho constituye el quebrantamiento del rol del ciudadano (corporativo) fiel al Derecho; es decir, la manifestación de la culpabilidad jurídico-penal empresarial.

3.5. El nacimiento de rol del ciudadano corporativo fiel al Derecho conlleva el reconocimiento de un mínimo de igualdad a las empresas. Ahí radica el segundo equivalente funcional que, de esta manera, consiste en el establecimiento del sinalagma fundamental del Derecho penal (empresarial): libertad de autoorganización (empresarial) vs. responsabilidad por las consecuencias (de la actividad empresarial). Expresado con las palabras de Schünemann: "la legitimación de las sanciones económicas a la asociación puede verse en la autonomía de la asociación, a la cual el Derecho le adscribe fundamentalmente una libertad a la organización propia que, sin embargo, tiene como reverso tener que ser responsable por los resultados negativos de esa libertad". ${ }^{36} \mathrm{La}$

\footnotetext{
${ }^{32}$ Dicha situación ha sido puesta de relieve principalmente por Heine y constituye en gran medida la base de su planteamiento [vid. ahora sólo sus contribuciones HEINE, "Technischer Fortschritt im Spannungsverhältnis von Unternehmen, Gesellschaft und Staat - Neue Herausforderungen für das Recht”, en: SCHULTE (ed.), Technische Innovation und Recht. Antrieb oder Hemmnis?, 1997, pp. 57 y ss.; ÍD., "Strafrecht zwischen staatlicher Risikolenkung und gesellschaftlicher Selbstregulierung", en: LANGE (ed.), Gesamtverantwortung statt Verantwortungsparzellierung im Umweltrecht, 1997, pp. 208 y ss.].

${ }^{33}$ Sobre la idea del Derecho reflexivo y el control del contexto vid. TEUBNER / WILLKE, "Kontext und Autonomie: Gesellschaftliche Selbststeuerung durch reflexives Recht", ZfRSoz № 5 (1984), pp. 4 y ss.; WILLKE, Ironie des Staates. Grundlinien einer Staatstheorie polyzentrischer Gesellschaft, 1992, pp. 185 y ss., 341 y ss.; ÍD., Supervision des Staates, 1997, pp. 72 y ss.; ÍD., Atopia. Studien zur atopischen Gesellschaft, 2001, pp. 131 y ss.; ÍD., Dystopia. Studien zur Krisis des Wissens in der modernen Gesellschaft, 2002, pp. 65 y ss.; ÍD., Heterotopia. Studien zur Krisis der Ordnung moderner Gesellschaften, 2003, pp. 122 y ss. En el ámbito jurídico-penal han sido HEINE [ÍD., Strafrechtliche Verantwortlichkeit, cit. nota $n^{\circ} 22$, pp. 49, 59 ss., 78 ss., 249 s.] y SCHÜNEMANN [ÍD., en: AA.VV., Hacia un Derecho penal económico europeo, p. 572; ÍD., en: SCHÜNEMANN (ed.), Deutsche Wiedervereinigung, pp. 138, 170, 175; ÍD., en: ESER / HEINE / HUBER (eds.), Criminal Responsibility of Collective and Legal Entities, cit. nota $\left.{ }^{\circ} 19, \mathrm{p} .232\right]$ quienes han adoptado principalmente estos dos conceptos para fundamentar sus modelos, si bien el primero apuesta, como aquí, por un verdadero Derecho penal empresarial, mientras que el segundo por un Derecho penal empresarial de medidas (Cfr. para una crítica de este aspecto de la construcción de Schünemann vid. GÓMEZ-JARA DÍEZ, La culpabilidad penal, cit. nota $\mathrm{n}^{\circ} 1$, pp. 277 y ss., 280).

${ }^{34}$ Para una fundamentación de este postulado vid. GÓMEZ-JARA DÍEZ, La culpabilidad penal, cit. nota ${ }^{\circ}$ 1 , pp. 261 y ss.

35 Vid. a este respecto JAKOBS, Norm, Person, Gesellschaft. Vorüberlegungen zu einer Rechtsphilosophie, $2^{\mathrm{a} e d .} 1999$, pp. 83 y ss., 86.

${ }^{36}$ SCHÜNEMANN, en: ÍD., (ed.), Deutsche Wiedervereinigung, cit. nota ${ }^{\circ} 19$, p. 170 [sin subrayado en el original].
} 
GÓMEZ-JARA, CARLOS. "Responsabilidad penal de todas las personas jurídicas? Una antecrítica al símil de la ameba acuñado por Alex van Weezel”.

institución negativa ${ }^{37}$ del nenimen laedere empresarial encuentra su anclaje constitucional, en de opinión de varios autores, en la libertad de empresa, ${ }^{38}$ y lleva aparejado la obligación, al igual que en el individuo, ${ }^{39}$ de mantener el ámbito de organización (empresarial) propio dentro de los márgenes del riesgo permitido. ${ }^{40}$ De esta manera se acentúa la autorresponsabilidad empresarial, que con Heine puede formularse como un imperativo categórico: toda empresa debe comportarse (organizarse) autorresponsablemente de tal manera que nadie resulte dañado - es decir, que el riesgo permanezca dentro del ámbito empresarial. ${ }^{41}$ La empresa pasa de ser un mero actor económico basado en la lógica racional de los costes/beneficios a convertirse en una persona jurídico-penal orientada por el esquema derechos/deberes; ${ }^{42}$ es decir, se constituye como un verdadero ciudadano fiel al Derecho.

3.6. Precisamente ese status de ciudadanía conforma el tercer equivalente funcional. Así, resulta fundamental para la dimensión material de la culpabilidad jurídico-penal la posibilidad de poder participar en la producción común de sentido; es decir, el principio de culpabilidad garantiza que la persona "es competente para intervenir en asuntos públicos". ${ }^{43}$ Sin embargo, ¿cómo participa la empresa en la producción común de sentido? ¿Cómo interviene en los asuntos públicos? El punto de partida viene dado por una determinada interpretación de la libertad de expresión reconocida constitucionalmente a las personas jurídicas. ${ }^{44}$ En este sentido, lo relevante a estos efectos no es tanto el reconocimiento en sí, sino el contenido y significado de dicha libertad. En este sentido resultan especialmente relevantes las consideraciones de Lawrence Friedman, ${ }^{45}$ quien trae a colación la sentencia

\footnotetext{
${ }^{37}$ Sobre las instituciones y los deberes negativos vid. JAKOBS, La imputación penal de la acción y de la omisión, SÁNCHEZ VERA, Javier (trad.), 1996, y pp. 27 y ss.; ÍD., Sobre la normativización de la dogmática jurídico-penal, pp. 27 y ss.; SÁNCHEZ-VERA GÓMEZ-TRELLES, Delito de infracción de deber y participación delictiva, 2002, pp. 83 y ss.

38 BOTTKE, wistra 1997, p. 253; HEINE, St.L.War.Tr.L.Rev. 1998, p. 179; Íd., ALWART (ed.), Verantwortung und Steuerung, cit. nota $\mathrm{n}^{\circ} 23$, p. 93.

${ }^{39}$ Vid., por ejemplo, JAKOBS, Sobre la normativización de la dogmática jurídico-penal (traducción de Manuel Cancio Meliá y Bernardo Feijóo Sánchez), 2003, p. 108; ÍD., "Competencia por organización en el delito omisivo. Consideraciones sobre la superficialidad de la distinción entre comisión y omisión” (traducción de Enrique Peñaranda Ramos), en: ÍD., Estudios de Derecho penal, 1997, p. 350.

${ }^{40}$ BOTTKE, Assoziationsprävention, cit. nota ${ }^{\circ} 19$, pp. 62 y ss. y las notas que acompañan al texto; HEINE, St.L.War.Tr.L.Rev., cit. nota $\mathrm{n}^{\circ} 38$, pp. 178 y ss.

${ }^{41}$ HEINE, Strafrechtliche Verantwortlichkeit, cit. nota $\mathrm{n}^{\circ} 22$, pp. 276 y s. con referencias a otras posturas semejantes. Vid. también STRATENWERTH, "Strafrechtliche Unternehmenshaftung?", en: GEPPERT et al (eds.), Festschrift für Rudolf Schmitt zum 70. Geburtstag, 1992, p. 307, derivando de ello, sin embargo, otras consecuencias.

42 Sobre la importancia de este paso vid. JAKOBS, "La imputación jurídico-penal y las condiciones de vigencia de la norma" (traducción de Javier Sánchez-Vera Gómez-Trelles y Carlos Gómez-Jara Díez), en: GÓMEZ-JARA DÍEZ (ed.), Teoría de sistemas y Derecho penal, cit. nota $n^{\circ} 16$.

${ }^{43}$ JAKOBS, Sobre la normativización, cit. nota $\mathrm{n}^{\circ} 39$, p. 50.

${ }^{44}$ Vid. ya las reflexiones de JELLINEK, System der subjektiven öffentlichen Rechte, (reimpresión de la

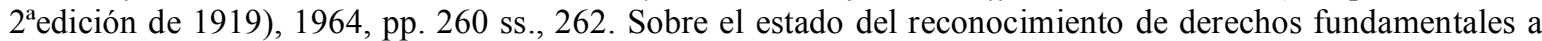
las personas jurídicas vid. HENNING, "The Connundrum of Corporate Criminal Liability: Seeking a Consistent Approach to the Constitutional Rights of Corporations in Criminal Prosecutions", Tenn.L.Rev. $\mathrm{N}^{\circ}$ 63 (1996), pp. 793 y ss.

${ }^{45}$ FRIEDMAN, "In Defense of Corporate Criminal Liability", Harvard Journal of Law \& Public Policy $\mathrm{N}^{\circ}$ 23 (2000), pp. 833 y ss.
} 
Polit. crim. Vol. 5, № 10 (Diciembre 2010), Doc. 1, pp. 455-475.

[http://www.politicacriminal.cl/Vol_05/n_10/Vol5N10D1.pdf]

de la Corte Suprema estadounidense First National Bank of Boston vs. Belloti. ${ }^{46}$ Así, en relación con la libertad de expresión de expresión reconocida a las corporaciones, dicha Corte declaró expresamente que se trataba de "la expresión o discurso que resulta indispensable para la toma de decisiones en la democracia, y ello no es menos cierto por el hecho de que la expresión provenga de una corporación en lugar de un individuo". ${ }^{47}$ De esta manera se viene entendiendo que, si bien una corporación como tal no puede votar, sí que se le reconoce el derecho a participar en lo que realmente cuenta en democracia: el debate entre los ciudadanos. En definitiva, a las corporaciones, al igual que a los individuos, se les reconoce un derecho a participar en el proceso de creación y definición de las normas sociales. ${ }^{48}$ Dicho proceso no viene marcado por el derecho de voto sino principalmente por la libertad de expresar juicios en el discurso público sobre las normas sociales, contribuyendo así a la conformación de las mismas. ${ }^{49}$

${ }^{46} 435$ U.S. 765 (1978).
${ }^{47} 435$ U.S. 765 (1978) 777.
${ }^{48}$ Vid. el desarrollo en GÓMEZ-JARA DÍEZ, La culpabilidad penal, cit. nota $n^{\circ} 1$, pp. 288 y ss. La relevancia de este reconocimiento depende en gran medida del posicionamiento que se adopte respecto al fundamento material del concepto de culpabilidad. Así, dicho reconocimiento resulta decisivo para una concepción de la culpabilidad en la cual la legitimidad de la pena y del consiguiente reproche de culpabilidad se vinculan a la posibilidad de participar en la conformación de la norma y, de esta manera, poder cuestionar la vigencia de la misma sin tener que recurrir a la comisión de un delito que porte dicho significado [vid. a este respecto partiendo de la perspectiva comunicativa JAKOBS, en: GÓMEZ-JARA DÍEZ (ed.), Teoría de sistemas y Derecho penal, cit. nota $\mathrm{n}^{\circ}$ 16; GÓMEZ-JARA DÍEZ, La culpabilidad penal, cit. nota $\mathrm{n}^{\circ} 1$, pp. 295 y ss.; desde una perspectiva intersubjetiva vid. GÜNTHER, "Strafrechtliche Verantwortlichkeit in der Zivilgesellschaft", en: PRITTWITZ / MANOLEDAKIS (eds.), Strafrechtsprobleme an der Jarhtausendwende. Deutsch-Griechisches Symposium Rostock 1999, 2000, pp. 27 y ss., 39; y KINDHÄUSER, "La fidelidad al Derecho como categoría de la culpabilidad” (traducción de Percy García Cavero), en: LUZÓN PEÑA / MIR PUIG (Coords.), Cuestiones actuales de la teoría del delito, 1999, pp. 185 y ss., 204, planteamiento que se deduce igualmente de las posiciones de PEÑARANDA RAMOS, "Sobre la influencia del funcionalismo y la teoría de sistemas en las actuales concepciones de la pena y del delito", en: GÓMEZ-JARA DÍEZ (ed.), Teoría de sistemas y Derecho penal, cit. nota $\mathrm{n}^{\circ} 16$, y ALCÁCER GUIRAO, "Prevención y garantías: conflicto y síntesis", DOXA N²5 (2002), pp. 139 y ss. Otra cuestión, que pese a su relevancia para esta discusión no se puede tratar aquí, es la relación entre intersubjetividad y comunicación (vid. al respecto LUHMANN, "Intersubjetividad o comunicación: dos diferentes puntos de partida para la construcción sociológica", en: ÍD., Complejidad y modernidad: de la unidad a la diferencia (edición y traducción a cargo de Josetxo Beriain y José María García Blanco), 1998, pp. 31 ss.; FEIJÓO SÁNCHEZ, en: GÓMEZ-JARA DÍEZ (ed.), Teoría de sistemas y Derecho penal, cit. nota ${ }^{\circ}$ 16; desde la denominada teoría expresiva de la pena vid. KAHAN / NUSSBAUM, "Two Conceptions of Emotion in Criminal Law", Columbia Law Review No 96 (1996), pp. 269 y ss., 351; KAHAN, "Between Economics and Sociology: The New Path of Deterrence", Michigan Law Review N 95 (1997), pp. 2477 y ss.; ÍD., "The Secret Ambition of Deterrence", Harvard Law Review N 113 (1999), pp. 413 y ss.; ÍD., "Social Meaning and Economics Analisis of Crime", Journal of Legal Studies $\mathrm{N}^{\circ} 27$ (1998), pp. 609 y ss.; FRIEDMANN, H.J.L.\&Pub.Pol. $\mathrm{N}^{\circ}$ 23 (2000), 845 y s.; en parte también ROBINSON, "Why Does the Criminal Law Care What the Layperson Think is Just? Coercive versus Normative Crime Control”, Virginia Law Review N 86 (2000), pp. 1839 y Ss.].

${ }^{49}$ Esta cuestión se encuentra relacionada con la posibilidad de considerar que las empresas son "miembros de pleno derecho de la comunidad moral" (full-fledge members of moral community), [vid. al respecto FRENCH, "Integrity, Intentions and Corporations", American Business Law Journal No 34 (1996), pp. 147 y ss.; FRENCH / NESTERUK / RISSER, Corporations in the Moral Community, 1992, pp. 12 ss.]. Sin embargo, a diferencia de estos autores, el planteamiento aquí sostenido no pretende una equiparación absoluta entre empresas e individuos en este sentido, sino sólo el reconocimiento de un mínimo de ciudadanía suficiente para el establecimiento de la responsabilidad penal. 
GÓMEZ-JARA, CARLOS. "Responsabilidad penal de todas las personas jurídicas? Una antecrítica al símil de la ameba acuñado por Alex van Weezel”.

3.7. Una vez explicitados estos fundamentos del concepto constructivista de culpabilidad jurídico-penal empresarial se puede abordar desde una nueva óptica el contenido de las críticas formuladas al comienzo de este trabajo. Como se advertirá claramente a lo largo de las líneas que siguen, la adopción de las premisas sentadas influye decisivamente en la consideración de qué organizaciones empresariales pueden delinquir - estando por ello sujetas a la imposición de una pena - y cuáles no - estando, así, sujetas a otro tipo de sanciones -. Asimismo, se podrá constatar que el modelo de responsabilidad penal empresarial subyacente a este planteamiento es un modelo de autorresponsabilidad (Selbstverantwortung), que, a diferencia de los modelos de heterorresponsabilidad, ${ }^{50}$ centran su atención en la conformación de una culpabilidad propia de la empresa y no en la atribución a la empresa de una culpabilidad ajena - sc. la de sus órganos o representantes -

\section{Aplicación de los presupuestos constructivistas a la crítica de partida}

4.1. Como se puede apreciar fácilmente en la exposición de la crítica de Rodríguez Mourullo, la conciencia, ese substrato psíquico, muestra unas cualidades especiales que son imprescindibles para la imputabilidad de la persona en Derecho penal; es decir, para ser sujeto activo de delito o, expresado de otra manera, para ser persona jurídico-penal activa. ${ }^{51}$ La cuestión es, por tanto, qué cualidades son esas que se muestran tan decisivas en el tema aquí tratado. El fundamento último de dichas cualidades reside en la autorreferencialidad de la conciencia, es decir, en la autoconciencia. ${ }^{52}$ Obvia realizar aquí consideraciones sobre la importancia que la conciencia humana ha tenido no ya para la discusión jurídico-penal, ${ }^{53}$ sino para numerosos debates filosóficos, de entre los cuales destaca el relativo a la identidad de la persona. ${ }^{54} \mathrm{Y}$ es que las características de la autoconciencia (Selbstbewußtsein) han sido todo un referente en la identificación de la autodeterminación del hombre, lo cual, desde el punto de vista de la cuestión en torno al libre albedrío y el nacimiento de la consiguiente responsabilidad (penal), posee una importancia cardinal.

4.2. En este sentido, merece la pena traer a colación la argumentación desarrollada recientemente por Molina Fernández en uno de los últimos y más profusos estudios sobre una cuestión tan debatida como es la libertad como presupuesto de la responsabilidad. ${ }^{55}$

\footnotetext{
${ }^{50}$ Para la distinción entre modelos de autorresponsabilidad y de heterorresponsabilidad vid. GÓMEZ-JARA DÍEZ, La culpabilidad penal, cit. nota $\mathrm{n}^{\circ} 1$, pp. 74 y ss.

51 Sobre el concepto de persona jurídico-penal activa vid. JAKOBS, en: PRITTWITZ ET AL, (eds.); Festschrift für Klaus Lüderssen, p. 566; más desarrollado en ÍD., Sobre la normativización de la dogmática jurídico-penal, pp. 22 y ss.

${ }^{52}$ Así, vid. JAKOBS, en: PRITTWITZ ET. AL., (eds.); Festschrift für Klaus Lüderssen, cit. nota n 51, p. 568: "Sólo una persona a la que se le atribuye una autoconciencia comunicativamente competente, puede comportarse de manera culpable".

53 Sobre la importancia de la autorreferencialidad de la conciencia para la conformación de la persona jurídico-penal vid. PAWLIK, Das unerlaubte Verhalten beim Betrug, 1999, pp. 8 y ss., 18 y ss., 31 y ss. con abundantes referencias.

${ }^{54}$ Vid., sobre el debate actual, las contribuciones contenidas, por ejemplo, en MARQUARD / STIERLE (eds.), Identität. $2^{\mathrm{a}}$ ed., 1996; QUANTE, Personale Identität, 1999. Para una visión teórico-sistémica del problema vid. LUHMANN, "Identität - was oder wie?", en: ÍD., Soziologische Aufklärung. Bd. V: Konstruktivistische Perspektiven, 1990, pp. 14 y ss.

${ }^{55}$ MOLINA FERNÁNDEZ, "Presupuestos de la responsabilidad jurídica. (Análisis de la relación entre libertad y responsabilidad)", Anuario de la Facultad de Derecho de la UAM N 4 (2000), pp. 57 y ss.
} 
Polit. crim. Vol. 5, № 10 (Diciembre 2010), Doc. 1, pp. 455-475.

[http://www.politicacriminal.cl/Vol_05/n_10/Vol5N10D1.pdf]

Este autor explica detalladamente en su exposición cómo se produce una evolución paulatina en los niveles de complejidad del sistema psíquico, al final de la cual se alcanza una "razón de segundo nivel" o "de segundo orden" caracterizada por la reflexión de la conciencia sobre sí misma: "el sujeto elabora conscientemente su elección con autorreferencia a la propia elección (..)" de tal manera que, "la conciencia introduce un elemento causal de segundo orden - la reflexión sobre el propio proceso de decisión - $\mathrm{y}$, con ello una elección externamente necesaria se convierte en internamente contingente". ${ }^{5}$

4.3. Como se advierte en las consideraciones realizadas hasta ahora se ha empleado el término "sistema" para hacer referencia a lo que tradicionalmente se denomina "ser humano". Esto se ha hecho deliberadamente para evitar el prejuicio antropocéntrico que, por lo general, domina todas las discusiones sobre la capacidad de responsabilidad penal de las personas jurídicas. ${ }^{57} \mathrm{Y}$ ello fundamentalmente porque dicho prejuicio, o mejor dicho preconocimiento (Vorverständnis), imposibilita en gran medida el desarrollo de una teoría jurídica del delito para las personas jurídicas. ${ }^{58}$ En efecto, la atribución al ser humano de ciertas cualidades - de cierto "equipamiento" 59 - que no concurren en la persona jurídica ha desembocado, indefectiblemente, en la exclusión de la persona jurídica del Derecho penal.

4.4. Sin embargo, es precisamente esa posición excluyente del ser humano como sujeto cognoscente la que ha venido a cuestionar la teoría de los sistemas sociales autopoiéticos. En efecto, esta teoría, apoyándose en los avances de las ciencias de la comunicación, ${ }^{60}$ parte de la base de que tanto conciencia como comunicación muestran los mismos caracteres de

\footnotetext{
${ }^{56}$ MOLINA FERNÁNDEZ, cit. nota $n^{\circ} 55$, p. 128.

${ }^{57}$ La expresión de "prejuicio antropocéntrico" (anthropocentric bias) en esta discusión ha sido acuñada, por lo que se alcanza a ver, por FRENCH, "The Corporation as a Moral Person", American Phisophical Quarterly $\mathrm{N}^{\circ} 16$ (1979), p. 214. Vid. también LAUFER, "Corporate Culpability and the Limits of Law", Business Ethics Journal No 6 (1996), p. 311; WALT / LAUFER, "Why Personhood doesn't matter. Corporate Criminal Liability and Sanctions", American Journal of Criminal Law and Criminology $\mathrm{N}^{\circ} 18$ (1991), pp. 264 y s. Por otro lado, se habla de un "modelo antropomórfico de responsabilidad" (anthropomorphes Verantwortlichkeitsmodell) [HEINE, "Europäische Entwicklungen bei der strafrechtlichen Verantwortlichkeit von Wirtschaftsunternehmen und deren Führungskräften”, ZStrR N 119 (2001), p. 35];

${ }^{58}$ Vid. en este sentido GARCÍA ARÁN, "Algunas consideraciones sobre la responsabilidad penal de las personas jurídicas”, en: CEREZO MIR ET. AL. (eds.), El nuevo Código Penal: presupuestos y fundamentos. Libro Homenaje a D. Angel Torío López, 1999, pp. 327, 331. Con acierto ALWART, "Strafrechtliche Haftung des Unternehmens - von Unternehmenstäter zum Täterunternehmen”, ZStW $\mathrm{N}^{\circ} 105$ (1993), pp. 756 y s., 761, 765 y s.; ÍD., Zurechnen und Verurteilen, 1998, pp. 9 y ss., 24 y ss. relaciona el problema de la responsabilidad penal empresarial con la hermeneútica de la imputación y es que, en realidad, esta problemática tiene relación con la cuestión hermeneútica del círculo del entendimiento (Zirkel des Verstehens): vid. HEIDEGGER, Sein und Zeit, 1927, § 32; GADAMER, Wahrheit und Methode. Grundzüge einer philosophischen Hermeneutik, 1960, pp. 270 y ss.

59 JAKOBS, en: PRITTWITZ ET. AL., (eds.), Festschrift für Klaus Lüderssen, cit. nota n ${ }^{\circ}$ 51, p. 571: "Ausstattung".

${ }^{60}$ Vid. ya MERTEN, Kommunikation: Eine Begriffs- und Prozessanalyse, 1977, pp. 43 y ss. y passim. Sobre el concepto de comunicación utilizado en la teoría de los sistemas sociales autopoiéticos vid., entre otras, las reflexiones de BAECKER, "Kommunikation im Medium der Information", en: BAECKER, Wozu Systeme?, 2002, pp. 111 y ss.; LUHMANN, Soziale Systeme, pp. 191 y ss.; ÍD., Die Wissenschaft der Gesellschaft, 1990, pp. 21 ss.; ÍD., “Was ist Kommunikation?”, en: LUHMANN, Soziologische Aufklärung, cit. nota n 21, pp. 113 y ss.; NASSEHI, "La diferencia de la comunicación y la comunicación de la diferencia. Sobre los fundamentos de la teoría social de Niklas Luhmann" (traducción de Juan Ignacio Piña Rochefort), en: GÓMEZ-JARA DÍEZ (ed.), Teoría de sistemas y Derecho penal, cit. nota ${ }^{\circ} 16$.
} 
GÓMEZ-JARA, CARLOS. "Responsabilidad penal de todas las personas jurídicas? Una antecrítica al símil de la ameba acuñado por Alex van Weezel”.

autorreferencialidad, recursividad y reflexión. ${ }^{61}$ A los efectos de la discusión aquí tratada, dicha autorreferencialidad comunicativa se da en dos sistemas claves: el sistema jurídico (Derecho) y el sistema organizativo (empresa). Por lo que al primero se refiere, la autorreferencialidad de la comunicación conlleva que el sistema jurídico no tenga acceso directo ni al interior de la conciencia humana (sistema psíquico), ni al interior de la organización empresarial (sistema organizativo). ${ }^{62}$ Ambos sistemas, tanto psíquico como organizativo, pueden aspirar, como mucho, a mostrar indicios racionales de una autorreferencialidad suficiente, ${ }^{63}$ ya que éstos conforman la base sobre la cual el sistema jurídico-penal atribuye la "personalidad". 64 Dicha autorreferencialidad se plasma, en terminología teórico-sistémica, en la constitución de los sistemas autopoiéticos de orden superior (High Order Autopoyetic Systems). ${ }^{65}$ Dado que la constitución del sistema psíquico (ser humano) como un sistema autopoiético de orden superior no es cuestionada por la doctrina penal mayoritaria - y es precisamente el proceso que describía anteriormente Molina Fernández -, conviene centrar la atención en el sistema organizativo (la empresa) para responder a la cuestión: ¿puede una organización empresarial convertirse en un sistema autopoiético de orden superior?

4.5. A lo largo de las últimas décadas, Gunther Teubner ha venido elaborando los presupuestos de cómo se constituye una empresa en un sistema autopoiético de orden superior. ${ }^{66}$ Así, tal y como señala expresamente este autor, la organización empresarial sale de su minoría de edad (Unmündigkeit) en el momento en el que se produce una vinculación hipercíclica entre los caracteres autorreferenciales del sistema organizativo: es decir, una doble autorreferencialidad. ${ }^{67}$ Expresado de otra manera: a lo largo del tiempo se produce una acumulación de círculos autorreferenciales en el ámbito empresarial hasta llegar al encadenamiento hipercíclico de los mismos, momento en el cual emerge verdaderamente el

${ }^{61}$ Vid. explicativo LUHMANN, "Die operative Geschlossenheit psychischer und sozialer Systeme", en: ÍD., Soziologische Aufklärung, cit. nota ${ }^{\circ} 21$, pp. 25 y ss.

62 Vid. sobre los fundamentos y consecuencias de este planteamiento LUHMANN, Das Recht der Gesellschaft, cit. nota $\mathrm{n}^{\circ} 21$, pp. 39 y ss.

63 Vid. fundamentalmente FUCHS, "Adressabilität als Grundbegriff der soziologischen Systemtheorie", Zeitschrift für soziale Systeme $\mathrm{N}^{\circ} 3$ (1997), pp. 57 y ss.

${ }^{64}$ Vid. sobre la autorreferencialidad interna como base para la atribución de subjetividad TEUBNER / ZUMBANSEN, "Rechtsverfremdungen: Zum gesellschaftlichen Mehrwert des zwölften Kamels", en: TEUBNER (ed.), Die Rückgabe des zwölften Kamels. Niklas Luhmann in der Diskussion über Gerechtigkeit, 2000, pp. 208 y ss.

${ }^{65}$ Vid. MATURANA, Erkennen: Die Organisation und Verkörperung von Wirklichkeit, 1982, pp. 37, 211 y ss.; MATURANA / VARELA, El árbol del conocimiento. Las bases biológicas del entendimiento humano. $15^{\mathrm{a}}$ ed., 2001, pp. 121 y ss.; MOSSAKOWSKI / NETTMANN, "Is There a Linear Hierarchy of Biological Systems?", en: ROTH / SCHWEGLER, Self-Organizing Systems. An Interdisciplinary Approach, 1981, pp. 39 y ss.

${ }^{66}$ Vid. TEUBNER, Law as an Autopoietic System, 1993, pp. 28 y ss., 123 y ss.; ÍD., "Enterprise Corporatism: New Industrial Policy and the "Essence" of the Legal Person", American Journal of Comparative Law $\mathrm{N}^{\circ} 36$ (1988), pp. 130 y ss.; ÍD., "Hyperzyklus in Recht und Organisation. Zum Verhältnis von Selbstbeobachtung, Selbstkonstitution und Autopoiese", en: HAFERKAMP / SCHMID (eds.), Sinn, Kommunikation und soziale Differenzierung. Beiträge zu Luhmanns Theorie sozialer Systeme, 1987, pp. 89 y ss., 113 y ss.; ÍD., "The Many-Headed Hydra: Networks as Higher-Order Collective Actors", en: MCCAHERY / PICIOTTO / SCOTT (eds.), Corporate Control and Accountability: Changing Structures and the Dynamics of Regulation, 1993, pp. 41 y ss.; ÍD., "Piercing the Contractual Veil? The Social Responsibility of Contractual Networks", en: WILHELMSSON (ed.), Perspectives of Critical Contract Law, 1993, pp. 211 y ss., 226 y ss.

${ }^{67}$ TEUBNER, "Hyperzyklus in Recht und Organisation", cit. nota n ${ }^{\circ}$ 66, p. 117. 
actor corporativo (corporate actor) como sistema autopoiético de orden superior. ${ }^{68}$ Dichos círculos autorreferenciales se dan en cuatro ámbitos diferenciados: el límite del sistema, la estructura del sistema, los elementos del sistema y la identidad del sistema. ${ }^{69}$ Así, el límite del sistema organizativo viene dado por la condición de miembro (Mitgliedschaft) $;{ }^{70}$ la estructura se materializa en los programas de decisión - tanto finales como condicionales que rigen en la organización; ${ }^{71}$ los elementos del sistema, esto es, las unidades basales u operaciones que constituyen la autopoiesis del sistema organizativo, son las decisiones; ${ }^{72}$ finalmente, la identidad del sistema viene determinada por la denominada identidad corporativa. ${ }^{73}$ Por lo tanto, cuando la identidad corporativa se vincula hipercíclicamente con la decisión corporativa, por un lado, y las normas del propio sistema son las que determinan quién es miembro de la organización, entonces surge el actor corporativo como una realidad diferente a la de cada uno de los sistemas psíquicos subyacentes y comienza a adquirir una capacidad autoorganizativa que excede con mucho la capacidad organizativa individual de cualquiera de sus miembros. $^{74}$

4.6. Por lo tanto, lo decisivo en el marco de esta discusión es que tanto el sistema psíquico como el sistema organizativo deben desarrollar una determinada complejidad interna suficiente para poder ser consideradas personas en Derecho penal. Así, la complejidad interna suficiente es un presupuesto para el desarrollo de una autorreferencialidad bastante que permita la autodeterminación del propio sistema con respecto al entorno ${ }^{75}$, cuestión decisiva para el nacimiento de la responsabilidad penal. En este sentido se puede establecer, de nuevo, una equivalencia funcional entre el desarrollo de una complejidad interna suficiente en el niño y en la organización empresarial. Así, al igual que el niño no es imputable en Derecho penal individual hasta que su sistema psíquico no es suficientemente complejo, esto es, hasta que no ha alcanzado un determinado nivel interno de autorreferencialidad - autoconciencia -, tampoco la empresa puede considerarse imputable en el Derecho penal empresarial hasta que su sistema organizativo no es suficientemente complejo, esto es, hasta que no ha alcanzado un determinado nivel interno de autorreferencialidad - autoorganización -. Por tanto, las empresas deben también superar

\footnotetext{
${ }^{68}$ TEUBNER, "Hyperzyklus in Recht und Organisation”, cit. nota ${ }^{\circ}$ 66, p. 112.

${ }^{69}$ Vid. el cuadro explicativo en TEUBNER, "Hyperzyklus in Recht und Organisation”, cit. nota n 66, p. 115.

${ }^{70}$ Sobre la condición de miembro vid. extensamente LUHMANN, Organisation und Entscheidung, cit. nota $\mathrm{n}^{\circ} 21$, pp. 81 ss., 112 ss.

${ }^{71}$ Sobre la programación del sistema vid. LUHMANN, Organisation und Entscheidung, cit. nota $\mathrm{n}^{\circ} 21$, pp. 256 y ss.

72 Sobre la decisión como base de los sistemas organizativos vid. LUHMANN, Organisation und Entscheidung, cit. nota n $^{\circ}$ 21, pp. 123 y ss.; ÍD., "Die Paradoxie des Entscheidens", Verw.Arch. N 84 (1993), pp. 287 y ss. Adicionalmente vid. BAECKER, Die Form des Unternehmens, 1993, pp. 152 y ss.; ÍD., Organisation als System, 1999, pp. 136 y ss.; WILLKE, Systemtheorie II: Interventionstheorie. $3^{\mathrm{a}}$ ed., 1999, pp. 151 y ss.

${ }^{73}$ Vid. LUHMANN, Organisation und Entscheidung, cit. nota n $^{\circ}$ 21, pp. 224 y s., 417 y ss., 438; WILLKE, Systemtheorie, cit. nota ${ }^{\circ} 17$, pp. 174 y ss.

${ }^{74}$ Vid. entre otros TEUBNER, Am.J.Comp.L. No 36 (1988), p. 140. De ahí que no deba resultar extraño que se produzca la denominada "irresponsabilidad organizada" [vid. sobre dicho concepto vid. BOSCH, Organisationsverschulden in Unternehmen, 2002, pp. 142 y ss.; HEINE, Strafrechtliche Verantwortlichkeit, cit. nota $\mathrm{n}^{\circ} 22$, pp. 31 y ss.; ROTSCH, Individuelle Haftung in Großunternehmen. Plädoyer für den Rückzug des Umweltstrafrechts, 1998, pp. 131 y ss.; FEIJÓO SÁNCHEZ, Sanciones para empresas, cit. nota $\mathrm{n}^{\circ} 10$, pp. 36 y ss.] puesto que en gran medida ésta surge en el momento en el que la empresa como tal va adquiriendo una capacidad de autoorganización.

${ }^{75}$ Vid. ahora sólo LUHMANN, Organisation und Entscheidung, cit. nota ${ }^{\circ}$ 21, p. 222.
} 
GÓMEZ-JARA, CARLOS. "Responsabilidad penal de todas las personas jurídicas? Una antecrítica al símil de la ameba acuñado por Alex van Weezel”.

ese umbral de complejidad interna suficiente y de autorreferencialidad bastante para poder ser consideradas personas en Derecho penal. Dicho umbral, por lo demás, se establece, tanto en el ámbito del Derecho penal individual como en el del Derecho penal empresarial, normativamente. Cómo debe entenderse esta circunstancia en este segundo ámbito será tratado a continuación en el epígrafe siguiente.

\section{Consecuencias teóricas y prácticas de la imputabilidad empresarial}

5.1. Antes que nada, deben realizarse una serie de consideraciones previas que contribuyen a reforzar la coherencia del planteamiento realizado hasta aquí. Es solamente en este contexto de la empresa como sistema autopoiético organizativo de orden superior que las anteriores reflexiones sobre la culpabilidad empresarial adquieren verdadero sentido. En efecto, sólo en el seno de una organización empresarial con una complejidad suficiente resulta posible institucionalizar una cultura de fidelidad al Derecho, de tal manera que la inexistencia de dicha cultura pueda concebirse como un déficit de fidelidad al Derecho, como un quebrantamiento del rol de ciudadano fiel al Derecho. De igual manera, sólo una empresa con una determina complejidad interna adquiere una capacidad autoorganizativa que permite asignarle una competencia por organización a la empresa $y$, en consecuencia, hacerla responsable por las consecuencias de dicha organización. Por último, únicamente una organización empresarial con una complejidad e importancia determinada puede participar en la conformación de las normas sociales, utilizando dicha posibilidad para cuestionar, en su caso, la vigencia de la norma sin necesidad de tener que recurrir a la comisión de un hecho delictivo. Una vez dicho esto, lo cierto es que pueden diferenciarse tres ámbitos, al menos, en los cuales este planteamiento despliega importantes consecuencias, tanto teóricas como prácticas.

5.2. El primer ámbito versa sobre la exclusión de las sociedades pantalla del ámbito de las penas del Derecho penal empresarial. ${ }^{76}$ En efecto, este tipo de sociedades no tienen desarrollada una complejidad interna suficiente que las dote de una autorreferencialidad bastante de cara al Derecho penal. De hecho, en el caso de las sociedades pantalla se aprecia claramente que se trata de sociedades plenamente heteroadministradas, carentes de la necesaria autonomía organizativa. Por ello, la adopción de cualquier tipo de medida de intervención frente a dichas sociedades se encuentra perfectamente legitimada, si bien no se pueden considerar verdaderas penas. Es decir, por supuesto que aquí no se aboga por la exclusión de sanciones o medidas de intervención contra las sociedades pantalla. Más bien todo lo contrario. Así, la utilización de este tipo de sociedades en el ámbito de delincuencia de cuello blanco y de la delincuencia organizada, entre otras, es sumamente habitual, por lo que se precisa de un instrumentario adecuado para tratar de manera eficaz con las mismas. Lo único que aquí se pretende es evitar que dicho instrumentario sea considerado un elenco de penas cuya imposición debe estar sujeta a la culpabilidad de la persona jurídica. Ello resulta, además, político-criminalmente adecuado, toda vez que, como se señalará, ${ }^{77}$ si se consideraran verdaderas penas, entonces su imposición estaría sujeta a requisitos y cautelas de constatación mucho más difícil - por no decir imposible -.

\footnotetext{
${ }^{76}$ Así ya se expresó en GÓMEZ-JARA DÍEZ, La culpabilidad penal, cit. nota n 1 , pp. 244 y ss.

${ }^{77}$ Vid. Infra V.
} 
5.3. El segundo ámbito donde se despliegan importantes consecuencias tanto teóricas como prácticas es el del levantamiento del velo, ámbito estrechamente relacionado con el primero. En efecto, desde que Bajo Fernández constató que la doctrina del levantamiento del velo parecía ir en contra de la tendencia hacia la responsabilidad penal de las personas jurídicas, ${ }^{78}$ varios autores se han sumado, con razón, a esta argumentación. ${ }^{79}$ Sin embargo, por parte de los defensores de esta responsabilidad no parecía proporcionarse una respuesta adecuada a esta crítica, de tal manera que la cuestión estaba claramente pendiente por resolver. Desde el planteamiento aquí expuesto puede ofrecerse una respuesta coherente de cómo compatibilizar la doctrina del levantamiento del velo con una responsabilidad penal de la persona jurídica; más aún, se puede indicar que dicha doctrina es el corolario natural de un sistema de autorresponsabilidad empresarial. Así, por un lado, resulta evidente que la figura del levantamiento del velo "transgrede" la personalidad jurídica de la empresa. Es decir, dicha técnica consiste precisamente en "rasgar" el velo jurídico de la sociedad para introducirse dentro de la misma y alcanzar a quienes la (hetero)administran. Más claramente no puede describirse la intromisión o intervención en una empresa. Por lo tanto, el levantamiento del velo es una técnica consistente en practicar, fundamentalmente en sociedades pantalla o sociedades que no han desarrollado una complejidad propia suficiente (por lo general de muy baja complejidad, aunque no siempre como en el caso de los grupos de empresas), una intervención de las mismas de tal manera que se intenta acceder a los responsables situados tras ellas (sean éstos individuos o empresas). ${ }^{80}$ Se trata, por tanto, de técnicas de intervención jurídico-penales.

5.4. Hasta aquí se han tratado dos ámbitos problemáticos, pero de solución relativamente sencilla. Cosa distinta ocurre en el tercer ámbito de estudio. Así, el principal problema en

\footnotetext{
${ }^{78}$ Vid. BAJO FERNÁNDEZ, "La responsabilidad de las personas jurídicas en el Derecho administrativo español", en: MIR PUIG / LUZÓN PEÑA (Coords.), Responsabilidad penal de las empresas y sus órganos y responsabilidad por el producto, cit. nota $\mathrm{n}^{\circ}$ 9, p. 5102; ÍD., "La responsabilidad penal de las personas jurídicas en el Derecho europeo actual", en: La responsabilidad penal de las sociedades. Actuación en nombre de otro, Responsabilidad de los Consejos de Administración. Responsabilidad de los subordinados. Cuadernos de Derecho judicial 1994, p. 117; ÍD., "Hacia un nuevo Derecho penal: el de las personas jurídicas", en: IGLESIAS PRADA (Coord.), Estudios jurídicos en homenaje al Profesor Aurelio Menéndez. Tomo IV. Derecho civil y Derecho público, 1996, p. 5102; ÍD., "Culpabilidad y persona jurídica", en: MARTÍNEZ-BUJÁN PÉREZ (Coord.); Congreso hispano-italiano de Derecho penal económico, 1998, p. 23. ${ }^{79}$ FEIJÓO SÁNCHEZ, Sanciones para empresas, cit. nota $n^{\circ}$ 10, p. 89; ÍD., "Sobre el fundamento de las sanciones penales para personas jurídicas y empresas en el Derecho penal español y el Derecho penal peruano", en: GARCÍA CAVERO (Coord.), La responsabilidad de las personas jurídicas, cit. nota $\mathrm{n}^{\circ} 11$, p. 242; SILVA SÁNCHEZ, "Responsabilidad penal de las empresas y de sus órganos en Derecho español", en: SILVA SÁNCHEZ (ed. española), Fundamentos de un sistema europeo de Derecho Penal. Libro Homenaje a Claus Roxin, 1995, p. 365; GONZÁLEZ GONZÁLEZ, "Consecuencias jurídico-penales aplicables a la persona jurídica en una futura reforma penal", La responsabilidad penal de las sociedades. Actuación en nombre de otro, Responsabilidad de los Consejos de Administración. Responsabilidad de los subordinados. Cuadernos de Derecho judicial, cit. nota $n^{\circ} 78$, p. 228. En general, sobre la problemática que circunda la doctrina del levantamiento del velo vid. SILVA SÁNCHEZ, "Ingeniería fiscal y Derecho penal", en: ROMÁN PUERTA (Dir.), Fenómenos delictivos complejos, 1999, pp. 172 y ss.; ÍD., “Artículo 31”, en: COBO DEL ROSAL (Dir.), Comentarios al Código penal, 1999, pp. 406 y ss.

${ }^{80}$ Por ello no resulta extraño que se haya propuesto reconducir esta técnica a la figura del administrador de hecho [vid. por todos SILVA SÁNCHEZ, en: ROMÁN PUERTA (Dir.), Fenómenos delictivos complejos, cit. nota $\mathrm{n}^{\circ}$ 79, pp. 174 y s.; ÍD., en: COBO DEL ROSAL (Dir.), Comentarios al Código penal, cit. nota n 79, p. 412, apuntando que, de esta manera, se salvan los obstáculos derivados de la prohibición de analogía in malem partem].
} 
GÓMEZ-JARA, CARLOS. "Responsabilidad penal de todas las personas jurídicas? Una antecrítica al símil de la ameba acuñado por Alex van Weezel”.

la materia, surge, al igual que en el ámbito del Derecho penal individual, en el establecimiento del límite normativo a partir del cual se puede considerar que una organización empresarial es una persona en Derecho penal sujeta a la imposición de una pena. En efecto, de la misma forma que resulta problemático fijar la mayoría de edad penal en el Derecho penal individual, también representa una importante dificultad fijarla en la empresa. Respecto de esta cuestión debe señalarse, en primer lugar, que dicho límite no es un límite ontológico sino normativo, por lo que, consiguientemente, puede variar en cada ordenamiento jurídico a la vista del grado de evolución y desarrollo de una sociedad. En segundo lugar, al igual que el substrato psíquico resulta determinante con respecto a la imputabilidad de los sistemas psíquicos (individuos) - como bien reflejaban las palabras de Rodríguez Mourullo -, el substrato organizativo deviene decisivo con respecto a los sistemas organizativos (empresas). De ahí que, a estos efectos, constituya un indicio decisivo la constitución de un substrato de organización formal (formal organization) ${ }^{81}$ para considerar que una empresa ostenta la condición de imputable en el Derecho penal empresarial. Por tanto, el acento no se pone ni en la personalidad jurídica, ni en la configuración económica, sino en el sistema social organizativo que subyace. ${ }^{82}$ Una vez planteadas así las cosas resulta posible concretar un poco más estos principios orientadores, anticipando, no obstante, que se trata de una tarea pendiente de desarrollar con mayor precisión.

5.5. Quizá deba comenzarse por aquellas sociedades sobre las cuales no existe duda respecto a su imputabilidad: las sociedades cotizadas. En efecto, este tipo de empresas han desarrollado ya un mínimo de complejidad interna suficiente y, de hecho, están sometidas a las obligaciones derivadas de la Ley 26/2003, de 18 de julio, sobre Transparencia y Buen Gobierno, que constituyen un reflejo, tal y como se señala expresamente en la propia Ley, del principio de autorregulación empresarial ${ }^{83}$ y que institucionalizan los Códigos de Buen Gobierno, ${ }^{84}$ íntimamente relacionados con los Códigos de Cumplimiento Efectivo

\footnotetext{
${ }^{81}$ Con respecto a la organización formal vid. LUHMANN, Funktionen und Folgen formaler Organisation, $4^{\mathrm{a}}$ ed. 1995, passim, con abundantes referencias.

${ }^{82}$ Vid. también en este sentido LESSENICH, Unternehmensbegriff und Zurechnung. Grundlage und Reichweite der Unternehmenspersonifizierung in Art. 15 der europäischen Kartellverordnung Nr. 17/62, 2000, pp. 76 ss., 84 y ss. En idéntico sentido se encaminan las “Organizational Sentencing Guidelines” del Derecho estadounidense, las cuales, como su propio nombre indica, giran en torno del concepto de organización. Así, resulta decisivo, el tipo de organización de que se trate a los efectos de determinar la pena de multa que debe imponerse [vid. UNITED STATES SENTENCING COMMISSION, United States Sentencing Guidelines, §8C2.5]. Por lo demás, parece que el límite normativo donde se sitúa la obligación de adquirir un programa de cumplimiento efectivo son los 50 empleados, puesto que si la empresa que resulta condenada tiene más de esa cantidad de empleados y no tiene el referido programa, entonces se establece una "Probation" obligatoria en la cual se implementa necesariamente. La tendencia general respecto de la importancia de la organización en este ámbito, se refleja igualmente en la reciente legislación polaca, en la cual se consideran sujetos colectivos a efectos de su responsabilidad penal tanto las personas jurídicas como las unidades organizativas sin personalidad jurídica (Art. 2. ap. $1^{\circ}$ de la Ley sobre la responsabilidad de sujetos colectivos por hechos castigados con penas).

${ }^{83}$ Vid. la Exposición de motivos del texto legislativo.

${ }^{84}$ Sobre el gobierno de las sociedad cotizadas vid., en general, SAN SEBASTIÁN FLECHOSO, El gobierno de las sociedades cotizadas y su control, 1996, pp. 651 y ss.; sobre los Códigos de Buen Gobierno vid., entre otros, ALONSO UREBA, "El gobierno de las grandes empresas (Reforma legal versus Código de Conducta)", en: ESTEBAN VELASCO (Coord.), El gobierno de las sociedades cotizadas, 1999, pp. 95 y ss.; FERNÁNDEZ DE LA GÁNDARA, "El debate actual sobre el gobierno corporativo: aspectos metodológicos
} 
Polit. crim. Vol. 5, № 10 (Diciembre 2010), Doc. 1, pp. 455-475.

[http://www.politicacriminal.cl/Vol_05/n_10/Vol5N10D1.pdf]

(Effective Compliance Programs) del Derecho penal empresarial estadounidense. ${ }^{85}$ Sin embargo, más allá de este sector empresarial en el cual no se plantean excesivas dudas respecto de su idoneidad para la cuestión aquí debatida, lo cierto es que se torna más complicado delimitar claramente qué complejidad interna es necesaria para poder considerar que una organización empresarial es imputable en el Derecho penal empresarial. $^{86}$

5.6. A la hora de establecer un/os criterio/s que guíen el establecimiento de la imputabilidad jurídico-penal empresarial deberían tenerse en cuenta las siguientes indicaciones. Así, en primer lugar, y como se deriva claramente de lo expuesto, no se puede considerar determinante ostentar la personalidad jurídica en sentido tradicional. Desde este punto de vista, el hecho de que una organización empresarial se constituya como persona jurídica en Derecho civil no implica, per se, que ostente personalidad jurídico-penal. Es decir, tanto en el Derecho penal individual como en el Derecho penal empresarial la personalidad jurídico-civil no implica la personalidad jurídico-penal. ${ }^{87}$ De ahí que, como se ha señalado, ciertas personas jurídico-civiles - v.gr. las sociedades pantalla - no sean personas jurídicopenales. En segundo lugar, lo determinante a estos efectos es la existencia de una organización empresarial con una determinada autorreferencialidad interna, lo cual puede venir indicado en gran medida por la existencia de procedimientos operativos estándar (Standard Operating Procedures) en el seno de la empresa. ${ }^{88}$ Así, dichos procedimientos fungen como premisas de decisión que dan cuenta de la sinergia y dinámica propias de la organización empresarial como tal. En tercer lugar, concurrirán importantes indicios de la constitución de un verdadero actor corporativo cuando la condición de miembro de la organización empresarial venga determinado por las normas de la propia organización y la identidad corporativa se institucionalice a través de ciertas decisiones corporativas.

y de contenido", en: ESTEBAN VELASCO (Coord.), El gobierno de las sociedades cotizadas, 1999, pp. 55 y ss., 64 y ss.; BORREGO RODRÍGUEZ / FRANCÉS, "El gobierno de las sociedades cotizadas en España", Papeles de Ética, Economía y Dirección $\mathrm{N}^{\circ} 5$ (2000), pp. 1 y ss.

${ }^{85}$ Sobre la relación entre los Códigos de Buen Gobierno y los Programas de Cumplimiento Efectivo vid. ahora LAUFER, "Corporate Liability, Risk Shifting, and the Paradox of Compliance", Vanderbilt Law Review $\mathrm{N}^{\circ} 52$ (1999), pp. 1397 y ss., así como las contribuciones contenidas en BASRI ET AL (eds.), Corporate Compliance: Caremark and the Globalization of Good Corporate Conduct, 1997. En la literatura jurídico-penal española vid. por todos NIETO MARTÍN, "El programa político-criminal del corporate goverment (Derecho penal de la empresa y gobierno corporativo)", $R D P P \mathrm{~N}^{\circ} 11$ (2004), pp. 259 y ss.; GÓMEZ-JARA DÍEZ, La culpabilidad penal, cit. nota $\mathrm{n}^{\circ} 1$, pp. 249 y ss.

${ }^{86}$ Ello resulta especialmente relevante, por ejemplo, a la hora de considerar si el grupo de sociedades es una organización empresarial sujeta a un régimen de responsabilidad penal. Vid. sobre las redes policorporativas como sistemas autopoiéticos de orden superior TEUBNER, en: MCCAHERY / PICIOTTO / SCOTT (eds.); Corporate Control and Accountability, cit. nota $\mathrm{n}^{\circ}$ 66, pp. 41 y ss.; ÍD., en: WILHELMSSON (ed.), Perspectives of Critical Contract Law, cit. nota $\mathrm{n}^{\circ}$ 66, pp. 226 y ss.; ÍD., Law as an Autopoietic System, cit. nota ${ }^{\circ}$ 66, pp. 123 y ss. Vid. también EMBID IRUJO, "Grupos y gobierno corporativo", en: ESTEBAN VELASCO (Coord.), El gobierno de las sociedades cotizadas, cit. nota ${ }^{\circ} 84$, pp. 600 y s.

${ }^{87}$ Vid. en este sentido HEINE, en: HETTINGER (ed.), Reform des Sanktionsrecht, cit. nota n ${ }^{\circ} 23$, p. 146.

${ }^{88}$ Sobre los procedimientos operativos estándar vid. ahora WILLKE, Systemtheorie III. Steuerungstheorie, $2^{\mathrm{a} e d .,}$ 1998, pp. 287 y ss.; sobre su influencia en el Derecho penal vid. ya KRIESBERG, "Decision making models and the Control of Corporate Crime", Yale Law Journal N 85 (1976), pp. 1091 y ss., 1100 y ss. 
GÓMEZ-JARA, CARLOS. "Responsabilidad penal de todas las personas jurídicas? Una antecrítica al símil de la ameba acuñado por Alex van Weezel”.

\section{Consideraciones sobre la conveniencia político-criminal de establecer una imputabilidad jurídico-penal empresarial}

6.1. Debido a la novedad que puede suponer distinguir entre personas jurídicas imputables e inimputables, podría llegar a concebirse que, de esta forma, se estarían dejando fuera del Derecho penal ciertas personas jurídicas de interacción habitual con el la normativa jurídico-penal, por lo que, en consecuencia, dicha distinción sería político-criminalmente poco recomendable. Precisamente para evitar dicho tipo de pensamientos en lo que sigue se finalizará esta modesta contribución con una serie de consideraciones respecto a la conveniencia político-criminal de establecer un criterio de imputabilidad en el seno del Derecho penal empresarial.

6.2. El punto de partida, como ya se ha señalado, consiste en afirmar que al igual que no todos los individuos son imputables en el Derecho penal individual, no todas las empresas pueden considerarse imputables en el Derecho penal empresarial. A partir de ahí, la primera ventaja político-criminal es que la imputabilidad jurídico-penal se corresponde con un modelo originario de responsabilidad penal empresarial. Este tipo de modelo se caracteriza, como ya han puesto de relieve algunos autores, ${ }^{89}$ por la estimulación de la autorresponsabilidad empresarial. Dicha estimulación se torna fundamental en el seno de una sociedad de riesgo en la que gran parte de sus riesgos característicos están sometidos al control quasi exclusivo de las organizaciones empresariales. En este sentido, el modelo de autorresponsabilidad penal empresarial facilita el control (descentralizado) del riesgo y la guía económica, dando respuesta a las necesidades sociales al mismo tiempo que respetanado la autonomía empresarial. ${ }^{90}$

6.3. La segunda ventaja político-criminal radica en que al estar vinculada la imputabilidad jurídico-penal con la capacidad de culpabilidad, la pena, caso de imponerse a organizaciones empresariales imputables, sigue manteniendo toda su significación jurídicopenal. Es decir, a diferencia de lo que ocurriría si se impusieran "penas" a, por ejemplo, sociedades pantallas carentes de cualquier viso culpabilidad propia, el significado comunicativo de la pena - restablecimiento comunicativo de la vigencia normativa - sigue manteniéndose cuando se refieren a organizaciones empresariales que tienen capacidad de generar una determinada cultura corporativa, que tienen una cierta presencia en la sociedad y que participan en el debate público sobre la conformación de las normas. Así, el mantenimiento de dicha significación comunicativa resulta fundamental a los efectos de distinguir, por ejemplo, entre el Derecho penal y el Derecho administrativo sancionador. ${ }^{91}$

\footnotetext{
${ }^{89}$ Vid. HEINE, Strafrechtliche Verantwortlichkeit, cit. nota ${ }^{\circ} 22$, pp. 253 y s., 279 y s.; ÍD., en: ALWART (ed.), Verantwortung und Steuerung, cit. nota ${ }^{\circ} 23$, p. 105; ÍD., en: SCHULTE (ed.), Technische Innovation und Recht, cit. nota $\mathrm{n}^{\circ}$ 32, pp. 68 y s., 74; ÍD., en: HETTINGER (ed.), Reform des Sanktionsrecht, cit. nota $\mathrm{n}^{\circ}$ 23, pp. 150 y s.; ÍD., St.L.War.Tr.L.Rev., cit. nota $\mathrm{n}^{\circ}$ 38, p. 179; BOTTKE, wistra 1997, cit. nota $\mathrm{n}^{\circ}$ 38, pp. 249 y ss.

90 Vid. extensamente HEINE, "Strafrecht zwischen staatlicher Risikolenkung und gesellschaftlicher Selbstregulierung: Kollektiv-Verantwortlichkeit als neue Steuerungsform”, en: LANGE (ed.), Gesamtverantwortung statt, cit. nota ${ }^{\circ} 23$, pp. 207 y ss.

${ }^{91}$ Vid. en este sentido recientemente, si bien expresado de la mano de la significación simbólica, MIR PUIG, "Una tercera vía", cit. nota $\mathrm{n}^{\circ}$ 9, p. 9, quien, no obstante, niega dicho carácter a las sanciones impuestas sobre las empresas. Distinta opinión manifiesta GUARDIOLA LAGO, Responsabilidad penal de las personas
} 
Polit. crim. Vol. 5, № 10 (Diciembre 2010), Doc. 1, pp. 455-475.

[http://www.politicacriminal.cl/Vol_05/n_10/Vol5N10D1.pdf]

6.4. La tercera ventaja político-criminal consiste en la consecuencia lógica que se deriva de la imputabilidad: la existencia de penas - a imponer con base en la culpabilidad jurídicopenal empresarial - y de medidas de seguridad - regidas por el principio de peligrosidad -. Expresado de otra manera; el Derecho penal empresarial puede conformarse como un Derecho penal de doble vía, de manera que se puede contar con un catálogo de sanciones más amplio con el cual afrontar la actividad delictivo-empresarial de forma más adecuada. Así, con independencia de la conocida crisis del sistema dualista en la actualidad, ${ }^{92}$ lo cierto es que las peculiares necesidades de adaptación de las sanciones a la compleja naturaleza de las organizaciones empresariales hace que resulte aconsejable contar con un amplio elenco de medidas y sanciones regidas por principios distintos. ${ }^{93}$

6.5. Por lo tanto, del contenido crítico de las reflexiones que Rodríguez Mourullo realizaba hace ya más de veinte años se ha extraído aquí, ante todo, la necesidad de que el modelo que rija el Derecho penal empresarial sea, al igual que en el Derecho penal individual, un modelo de autorresponsabilidad, de responsabilidad por la culpabilidad propia, y no de atribución de culpabilidad ajena. De ahí se deriva como corolario lógico la necesidad de distinguir entre organizaciones empresariales imputables e inimputables a los efectos de determinar los criterios de imputación y el tipo de sanción a imponer. Ello constituye un fiel reflejo de las matizaciones ya existentes en la sociedad moderna, donde no todas las empresas generan una determinada cultura empresarial o participan en la conformación de las normas. Por lo tanto, el Derecho penal, si pretende garantizar la identidad normativa de una sociedad, debe tener en cuenta esta idiosincrasia de la sociedad empresarial postindustrial en la que las organizaciones empresariales se constituyen como operadores jurídicos, económicos, políticos y sociales de primer orden.

jurídicas y alcance del art. 129 del Código penal, 2004, pp. 118 y s., quien, precisamente por el contenido simbólica de la pena frente a la sanción administrativa, aboga por mantener en carácter penal de las consecuencias accesorias del artículo 129 del Código penal vigente. Sobre la importancia de la dimensión comunicativa vid. GÓMEZ-JARA DÍEZ, "Die Strafe: eine systemtheoretische Beobachtung", Zeitschrift für Rechtstheorie $\mathrm{N}^{\circ} 36$ (2005) (en prensa).

92 Vid. por todos con referencias JORGE BARREIRO, Agustín, "Crisis actual del dualismo en el Estado social y democrático de Derecho", Modernas tendencias en el ciencia del Derecho penal y en la criminología, 2001, pp. 143 y ss., 149 y ss.

${ }^{93}$ Ahora bien, no se puede desconocer que la experiencia estadounidense demuestra la conveniencia políticocriminal de combinar penas con medidas de seguridad en el ámbito empresarial. Así, el ejemplo más claro viene dado por la "Organizational Probation", la cual, en principio, se conceptualiza como una medida de seguridad. Sin embargo, en las Directrices para condenar organizaciones se permite su uso para asegurar el pago efectivo de la pena de multa [vid. United States Sentencing Commission, United States Sentencing Guidelines, §8D.1.1.a)2] 